\title{
Breast milk pasteurisation in developed countries to reduce HIV transmission. Do the benefits outweigh the risks?
}

\author{
M. GILES ${ }^{1} \&$ A. MIJCH${ }^{2}$ \\ ${ }^{1}$ Department of Microbiology and Infectious Diseases, Royal Women's Hospital, Carlton VIC, Australia, and ${ }^{2}$ Victorian \\ HIV Service, The Alfred Hospital, Prahran VIC, Australia
}

\begin{abstract}
Background. Transmission of HIV through breastfeeding is well documented. The World Health Organisation advise HIVinfected women in developed countries to use alternatives to breastfeeding together with highly active antiretroviral therapy and optimal management of delivery to prevent transmission of HIV to their infant.

Case report. We present the case of an HIV-infected woman electing to exclusively breastfeed for six months and applying milk pasteurisation techniques without transmission to her infant. Two paired samples of her breast milk were tested for HIV RNA prior to and after pasteurisation. The first pair of specimens reported no change in HIV RNA copy number, the second pair of specimens reported an increase in copy number.

Discussion. This technique, the evidence for HIV inactivation and the effects pasteurisation has on nutritional and immunological components of breast milk are discussed.

Conclusion. In conclusion, we believe there is currently insufficient data to recommend this technique either as a safe alternative to formula feeding in resource-rich countries or as a method for providing intact immunological components of breast milk to the infant.
\end{abstract}

Keywords: HIV, pasteurisation, breast milk, immunological, breastfeeding, Holder technique, infection

\section{Introduction}

HIV has been detected in breast milk and transmission can occur at any point during lactation, the cumulative probability of infection increasing with the duration of breastfeeding. In a meta-analysis of late postnatal transmission (defined as an infant with negative HIV-1 result at 4 weeks of age followed by a positive test result) the overall risk was 8.9 transmissions per 100 child-years of breastfeeding (95\% confidence interval 7.8-10.2 transmissions $/ 100$ child years of breastfeeding) [1-3]. Factors associated with increased rates of HIV transmission include mixed feeding (breastfeeding supplemented by formula and other bottle feeding) [4] high maternal viral load, prolonged breastfeeding and breastfeeding in the presence of mastitis or breast abscesses [5,6].

In resource-rich countries breastfeeding is not recommended, but the World Health Organization suggests that breastfeeding should still be the usual advice to pregnant women in countries where infectious diseases and malnutrition are the main causes of infant deaths and infant mortality is high [7].
HIV is inactivated by heating and reports in the literature have suggested that pasteurisation in a domestic setting may be a method for enabling HIVinfected women to breastfeed [8]. We report the case of a woman attempting to apply the technique of breast milk pasteurisation in a developed country in order to enable her infant access to the benefits of breastfeeding (immunological, nutritional and psychological) and the results from testing her milk for HIV.

\section{Case report}

This case is of a 34-year-old woman who acquired her HIV in Africa in 1994 following a sexual contact. In January 1997 she commenced antiretroviral therapy comprising of zidovudine, lamivudine and indinavir. Her viral load dropped from 396000 copies/mL to undetectable. In July 1997 she ceased indinavir when she decided to become pregnant. After ceasing indinavir her viral load again became detectable at 1400 copies $/ \mathrm{mL}$. She soon became pregnant and continued on zidovudine and lamivudine for the remainder of her pregnancy. Her viral load remained

Correspondence: Dr M. Giles, MBBS, FRACP, Department of Microbiology and Infectious Diseases, Royal Women's Hospital, 132 Grattan St, Carlton VIC 3053, Australia. Tel: 6139282 2243. Fax: 6139344 3173. E-mail: michelle.giles@burnet.edu.au 
detectable throughout the pregnancy at low levels, ranging between 400 and 1000 copies/mL. In May 1998 she underwent an elective caesarean section, she did not breastfeed and her baby who received oral zidovudine syrup for six weeks, remained uninfected.

In February 1999 the patient ceased all antiretrovirals for a five-month period. Her viral load at this time peaked at greater than 750000 copies $/ \mathrm{mL}$ and her CD4 count dropped to 396 (28\%). She recommenced therapy in July 1999 with stavudine, lamivudine and efavirenz. Her viral load became undetectable and her CD4 count rose (ranging between 777 and 1000). The patient decided again to cease all medication in October 2001.

In July 2002, she presented eight weeks pregnant. At this time she was off antiretroviral therapy, her CD4 count was 550 (19\%) and her viral load 14000 copies $/ \mathrm{mL}$. The patient commenced antiretrovirals at 19 weeks gestation on zidovudine, lamivudine and nevirapine. She had an uneventful pregnancy and underwent an elective caesarean section in February 2003. At this time her viral load was undetectable. Her baby received oral zidovudine syrup and despite medical advice the patient proceeded to breastfeed using pasteurised breast milk after the first week. For the first week the patient used donor milk from a friend and did not pasteurise this. After the first week she exclusively breastfed and pasteurised her milk at home. The method of pasteurisation used was the Holder technique [9]. This involved heating water in an urn to $65^{\circ} \mathrm{C}$ then placing a sterilized jar containing the breast milk into the urn so the water level was over the milk level. A thermometer placed in the jar monitored the temperature and aimed to keep the milk at $64^{\circ} \mathrm{C}$ for $30 \mathrm{~min}$. The milk was then removed and provided to the infant in a bottle. This continued for six months and she did not report any mastitis or nipple problems during this time. She remained on the same antiretrovirals with her plasma viral load less than 400 copies $/ \mathrm{mL}$.

Two paired specimens of breast milk were analyzed pre- and post-pasteurisation for HIV viral load. The first paired specimens of breast milk were sent to the State Reference Laboratory for HIV and underwent HIV RNA quantification by NASBA. HIV RNA was detected at less than 250 copies $/ \mathrm{mL}$ both pre- and post-pasteurisation. The second pair of specimens were tested at the same State Reference Laboratory for HIV using the Roche ULTRA PCR (polymerase chain reaction) four months later and the breast milk sample prior to pasteurisation had 60 copies $/ \mathrm{mL}$ and the breast milk sample postpasteurisation had $80 \mathrm{copies} / \mathrm{mL}$. The methods and performance characteristics of these assays for quantification of HIV RNA in plasma have previously been described [10].
The patient's son tested at six months remained uninfected with HIV.

\section{Discussion}

HIV is easily inactivated by heat. Holder pasteurisation used by human milk banks $\left(56^{\circ} \mathrm{C}\right.$ for $30 \mathrm{~min}$ ) has resulted in the inactivation of all detectable virus by repeat culture in human milk inoculated with HIV [11]. A method called Pretoria pasteurisation has been devised in an attempt to heat the milk in a domestic environment in a way that prevents the milk becoming too hot and destroying immunological components although still reaching sufficient temperature for the inactivation of HIV [8]. This method involves heating a $1 \mathrm{~L}$ aluminium pot containing $450 \mathrm{~mL}$ of water to boiling then removing from the heat source and placing a jar containing $50-150 \mathrm{~mL}$ of milk into the water. By following this procedure the milk temperature remains between 56 and $62.5^{\circ} \mathrm{C}$ for between 10 and $15 \mathrm{~min}$. It is not clear whether $15 \mathrm{~min}$ is sufficient to inactivate all cell-free and cell-associated HIV in breast milk.

In an attempt to answer this question the same group of researchers performed a prospective observational study to test the effectiveness of Pretoria pasteurisation to inactivate HIV in human breast milk. Milk samples from HIV-seropositive women were split into two portions: a control and a study portion. These were sampled for HIV RNA and HIV DNA PCR and immediately inoculated into lymphocyte culture for 35 days. Twenty-six samples from HIV-seropositive women were tested. Eighty percent of these had viral RNA detected prior to pasteurisation (mean milk viral load 422000 copies/ $\mathrm{mL}$ ) but none of the pasteurised specimens showed increasing titres of viral RNA. In two of the specimens viral RNA was detectable in the pasteurised specimens but at low levels [12]. Of the HIV-positive control specimens, $18 \%$ had evidence of viral replication. In our case report, there is a relatively low level of virus detected in the milk sample prior to pasteurization, which may impact on the magnitude of effect demonstrable by pasteurisation, although it is important to note that the copy number did increase in the second specimen.

One of the main reasons why HIV-positive women in developed countries desire to breastfeed is to provide for their infant a source of milk that contains not only all their nutritional requirements but also has immunological components not found in formula feed. An important question therefore, is what does the process of heat pasteurisation do to these components?

Immunomodulating factors and antimicrobial agents found in breast milk include proteins such as lactoferrin (chelates iron), lysozyme (degrades peptidoglycans), fibronectin (acts as an opsonin), 
secretory IgA (antigen binding), mucin (fragments act as opsonins), lipids (known to disrupt enveloped viruses) and cytokines such as interleukin- $1 \beta$ and interleukin-6 (activates $\mathrm{T}$ cells and enhances IgA production) [13]. Pasteurisation at $62^{\circ} \mathrm{C}$ for $30 \mathrm{~min}$ leads to a reduction in IgA, lactoferrin, lysozyme, cell number and function [14].

Holder pasteurisation has also been shown to significantly lower the concentrations of vitamin C (36\%), folacin (31\%) and B6 (15\%) [15]. Pasteurisation also reduces enzyme activity including lipase, amylase and lactoperoxidase [16] along with serumstimulated lipolytic and serum-independent lipolytic activity [17].

As treatment and prognosis for HIV-seropositive women in resource-rich countries improves many are contemplating having children. Many interventions have been demonstrated to reduce perinatal transmission such as antiretroviral therapy [18] elective caesarean section [19] and avoidance of breastfeeding, although much of this benefit has been studied prior to the availability of highly active antiretroviral therapy (HAART). Studies have demonstrated that women with a higher breast milk viral load and those who shed virus consistently rather than intermittently are more likely to transmit HIV to their infants [6]. It is important to note that cell-associated HIV-1 provirus in the breast milk has been reported despite low/undetectable plasma viremia [20]. There is a paucity of data on additional risk of transmission via breastfeeding in women with undetectable viral load and who undertake additional measures such as milk pasteurisation.

The only antiretrovirals known to be excreted in human breast milk are zidovudine, lamivudine and nevirapine. Many of the remaining antiretrovirals have been found in breast milk in animal studies but lack data on excretion in human breast milk [21].

As clinicians looking after these women, it is essential that we are aware of the literature describing these techniques. As our case report highlights, HIVseropositive women may decide to access this information and apply these techniques to facilitate breastfeeding. The testing we employed demonstrated the presence of HIV post-pasteurisation. We believe it is essential to conduct further studies to assess the safety of this technique and to investigate the effect HAART may have on viral load pre- and post-pasteurisation. In such a study it would also be important to document more formally the effect this technique has on the many immunological factors present in breast milk as it is for this reason that many women are keen to breastfeed. Women infected with HIV in developed countries who desire to breastfeed and employ breast milk pasteurisation need to be informed regarding the effect this may have on inactivating HIV along with the potential adverse effects this process may have on the immunological components contained within breast milk. At this time we believe there is insufficient data to recommend this technique as a safe alternative to formula feeding in resource-rich countries.

\section{Acknowledgments}

Dr Giles gratefully acknowledges support from the Centre for Clinical Research Excellence Infectious Diseases.

\section{References}

1. Thiry L, Spencer-Goldberger S, Jonckheer T, Levy J, Van de Perre P, Henrivaux P, Cogniaux-LeClerc J, Clumeck N. Isolation of AIDS virus from cell-free breast milk of three healthy virus carriers. Lancet 1985;2(8460):891-892.

2. Ruff A, Coberly J, Burnley A, Boulos R, Desormeaux J, Halsey N, Farzadegan H, CDS/JHU AIDS Project Team. Prevalence of HIV in breast milk. VIII International Conference on AIDS, Amsterdam; 1992.

3. The Breastfeeding and HIV International Transmission Study Group. Late postnatal transmission of HIV-1 in breast-fed children: An individual patient data meta-analysis J Infect Dis 2004;189:2154-2166.

4. Coutsoudis A, Pillay K, Kuhn L, Coovadia HM. Influence of infant feeding patterns on early mother-to-child transmission of HIV-1 from mothers to children by 15 months of age: a prospective cohort study. South African Vitamin A Study Group. Lancet 1999;354:471-476.

5. Miotti PG, Taha TE, Kumwenda NI, Broadhead R, Mtimavalye LA, van der Hoeven L, Chiphangwi JD, Liomba G, Biggar RJ. HIV transmission through breastfeeding: a study in Malawi. JAMA 1999;282:744-749.

6. Sembra RD, Kumwenda NI, Hoover DR, Taha TE, Quinn TC, Mtimavalye L, Biggar RJ, Broadhead R, Miotti PG, Sokoll J, et al. Human immunodeficiency virus load in breast milk, mastitis and mother-to-child transmission of human immunodeficiency virus type 1. J Infect Dis 1999;180:93-98.

7. Global Programme on AIDS. Consensus statement from the WHO/UNICEF consultation on HIV transmission and breastfeeding. Weekly Epidemiology Record 1992;67:177-179.

8. Jeffery BS, Mercer KG. Pretoria pasteurisation: A potential method for the reduction of postnatal mother to child transmission of the human immunodeficiency virus. J Trop Pediatrics 2000;46:219-223.

9. Human Milk Banking Association of North America. Guidelines for establishment and operation of a donor human milk bank, Sandwich, MA: HMBANA; 1996.

10. Lin HJ, Pedneault L, Hollinger B. Intra-assay performance characteristics of five assays for quantification of human immunodeficiency virus type $1 \mathrm{RNA}$ in plasma. J Clin Micro 1998;36:835-839.

11. Orloff, SL, Wallingford, JC, McDougal, JS. Inactivation of human immunodeficiency virus type I in human milk: Effects of intrinsic factors in human milk and of pasteurisation. J Hum Lact 1993;9:13-17.

12. Jeffery BS, Webber L, Mokhondo KR, Erasmus D. Determination of the effectiveness of inactivation of human immunodeficiency virus by Pretoria pasteurisation. J Trop Pediatrics 2001;47:345-349.

13. Lawrence RA. Storage of human milk and the influence of procedures on immunological components of human milk. Acta Paediatr 1999;430 Suppl: 14-18. 
14. Evans TJ, Ryley HC, Neale LM, Dodge JA, Lewarne VM. Effect of storage and heat on antimicrobial proteins in human milk. Arch Dis Child 1978;53:239-241.

15. Van Zoeren-Grobben D, Schrijver J, Van Den Berg H, Berger HM. Human milk vitamin content after pasteurisation, storage or tube-feeding. Arch Dis Child 1987;62: 161-165.

16. Ford JE, Law BA, Marshall VM, Reiter B. Influence of the heat treatment of human milk on some protective constituents. J Pediatr 1977;90:29-35.

17. Jensen RG. Determinants of milk volume and composition. In: Jensen RG, editor. Handbook of milk composition, New York: Academic Press; 1995. pp 254-264.

18. Brocklehurst P. Interventions for reducing the risk of motherto-child transmission of HIV infection (Cochrane Review), The Cochrane Library; 2002.
19. The European Mode of Delivery Collaboration. Elective caesarean section versus vaginal delivery in prevention of vertical HIV-1 transmission: a randomized clinical trial. Lancet 1999;353:1035-1039.

20. Chantry CJ, Morrison P, Panchula J, Rivera C, Hillyer G, Zorilla C, Diaz C. Effects of lipolysis or heat treatment on HIV-1 provirus in breast milk. J Acquir Immune Defic Syndr 2000;24:325-329.

21. Safety and toxicity of individual antiretroviral agents in pregnancy. Supplement: Safety and toxicity, 23 June 2004. Available: www.aidsinfo.nih.gov/guidelines/default_db2.asp?id=66 


\title{
Letter to the Editor
}

\section{Breast Milk Pasteurization: Appropriate Assays to Detect HIV Inactivation}

\author{
Caroline J. Chantry, ${ }^{1}$ Barbara F. Abrams, ${ }^{2}$ Richard M. Donovan, ${ }^{3}$ \\ Kiersten A. Israel-Ballard, ${ }^{2}$ and Haynes W. Sheppard ${ }^{3}$ \\ ${ }^{1}$ Department of Pediatrics, University of California, Davis Medical Center, 2516 Stockton Boulevard, Room 334, Sacramento, \\ CA 95817, USA \\ ${ }^{2}$ Division of Epidemiology, School of Public Health, University of California, 140 Earl Warren Hall \#7360, Berkeley, \\ CA 94720-7360, USA \\ ${ }^{3}$ California Department of Health Services, Viral and Rickettsial Disease Laboratory, 850 Marina Bay Parkway, Richmond, \\ CA 94804, USA
}

Received 11 January 2006; Accepted 12 January 2006

Copyright () 2006 Caroline J. Chantry et al. This is an open access article distributed under the Creative Commons Attribution License, which permits unrestricted use, distribution, and reproduction in any medium, provided the original work is properly cited.

We read the recent article "Breast milk pasteurization in developed countries to reduce HIV transmission. Do the benefits outweigh the risks?" in Infectious Diseases in Obstetrics and Gynecology with great concern. The authors tested two paired specimens of heated and unheated breast milk using HIV RNA quantification (NASBA and Roche ULTRA PCR). They found no decrease in HIV RNA levels between the heated and unheated samples and thus concluded there to be insufficient data to recommend heat treatment as a safe alternative in resource-rich countries. We are particularly concerned that they have misinterpreted their results and that this confusion may be perpetuated in discussions and policies around the globe, most importantly in resource-poor regions.

We strongly encourage the authors, editors, and readership of your journal to reinterpret the results presented since the HIV detection method used by Giles and Mijch does not differentiate between active (infectious) and inactive (noninfectious) HIV in breast milk. Our team has been investigating the safety of heat-treated breast milk as an infant feeding option for mothers in developing countries and have recently published the results of pilot safety data [2]. We have designed a simple "flash-heat" treatment method that a mother could use in her home or over a fire, similar to commercial high-temperature, short-time (HTST) pasteurization. Although the study published by Chantry et al [3] used a similar heating method and demonstrated destruction of HIV proviral DNA in HIV-infected breast milk cells [3], the method used in that report achieved higher milk temperatures due to smaller milk volumes and Pyrex glass. In designing a more gentle heating method, we also found, as reported by Giles and Mijch, no decrease in HIV RNA.

We ascertained, however, that assaying for presence of $v i$ ral $R N A$, as performed by Giles in the above article, is not an adequate technique for detecting infectious virus in heated breast milk. Nucleic acid is very resistant to heating, up to the boiling point of water. It is to be expected that viral nucleic acid will remain postheating and will be detected by PCR-based assays even after the virus itself is rendered totally incapable of replication due to destruction of vital enzyme activities, structural proteins, and membrane structures due to the heat. We acknowledge that RNA detection is commonly used for quantification of HIV in both plasma and unheated breast milk. In order to determine the effect of heat on HIV in breast milk, however, the assay must effectively distinguish between live versus inactivated virus. We have demonstrated this in our recent pilot work comparing the flash-heat method with Pretoria pasteurization, another simple technique mentioned by Giles and Mijch [4, 5]. We found no decrease in cell-free HIV RNA as determined by TaqMan Real-time RNA PCR in breast milk (Log HIV RNA (SD) in unheated milk $=8.00(0.03)$ versus heated milk $=7.95(0.03))$. We recognized the need for an alternative assay to accurately assess virus viability and, as traditional coculture methods are difficult with breast milk due to the innate antiviral properties of the milk, we chose quantitative measurement of reverse transcriptase (RT) as a marker for viable HIV (ExaVir Quantitative Reverse Transcriptase Load 
Kit, Cavidi, Uppsala Sweden). In contrast to our TaqMan PCR data from the same samples, we found inactivation of $\geq 3$ logs of HIV-1 as detected by enzymatic activity of RT in postheated samples, with the flash-heat method more effectively eliminating RT than Pretoria pasteurization. We have subsequently confirmed these results by directly assaying for infectivity using transactivation of a green fluorescent protein (GFP) reporter group (data unpublished). Although we acknowledge that detection of HIV activity in breast milk can be challenging, we would encourage the authors to repeat their work using an appropriate assay.

We recognize the concerns mentioned by the authors regarding the impact of heat on vitamins, proteins, immunoglobulins, and the antimicrobial properties of breast milk. Low-temperature, long-time (LTLT) heat treatments, for example, Holder pasteurization, typically preserve nutrients less than HTST methods do. We reported pilot data suggesting limited impact on vitamins and proteins using flash-heat [2]. Our ongoing study is investigating the above concerns in-depth and we hope to have this data available in the near future.

We agree that it is not currently justifiable to recommend heat treatment of HIV-infected breast milk in resource-rich countries. However, we are concerned that the results, presented by Giles and Mijch of two heated breast milk samples demonstrating persistent HIV RNA being interpreted as "persistent HIV" without further exploration of viral infectivity, may have unwarranted repercussions. We strongly urge re-consideration of the results in light of our findings that HIV RNA is detectable after heating with no demonstrable activity of RT, which is necessary for virus to replicate. Heat treatment of breast milk is a recognized infant feeding option by the World Health Organization for HIV positive mothers who live in areas where no other alternatives are available. While we acknowledge that further research is needed, caution should be used when stating conclusions that may negatively impact policy makers' decisions regarding what may be appropriate in such communities.

\author{
Caroline J. Chantry \\ Barbara F. Abrams \\ Richard M. Donovan \\ Kiersten A. Israel-Ballard \\ Haynes W. Sheppard
}

[3] Chantry CJ, Morrison P, Panchula J, et al. Effects of lipolysis or heat treatment on HIV-1 provirus in breast milk. JAIDS: Journal of Acquired Immune Deficiency Syndromes. 2000;24(4):325-329.

[4] Jeffery BS, Mercer KG. Pretoria pasteurisation: a potential method for the reduction of postnatal mother to child transmission of the human immunodeficiency virus. Journal of Tropical Pediatrics. 2000;46(4):219-223.

[5] Jeffery BS, Webber L, Mokhondo KR, Erasmus D. Determination of the effectiveness of inactivation of human immunodeficiency virus by Pretoria pasteurization. Journal of Tropical Pediatrics. 2001;47(6):345-349.

\section{REFERENCES}

[1] Giles M, Mijch A. Breast milk pasteurisation in developed countries to reduce HIV transmission. Do the benefits outweigh the risks? Infectious Diseases in Obstetrics \& Gynecology. 2005;13(4):237-240.

[2] Israel-Ballard K, Chantry C, Dewey K, et al. Viral, nutritional, and bacterial safety of flash-heated and pretoria-pasteurized breast milk to prevent mother-to-child transmission of HIV in resource-poor countries: a pilot study. JAIDS: Journal of Acquired Immune Deficiency Syndromes. 2005;40(2):175-181. 


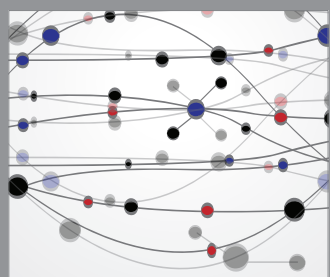

The Scientific World Journal
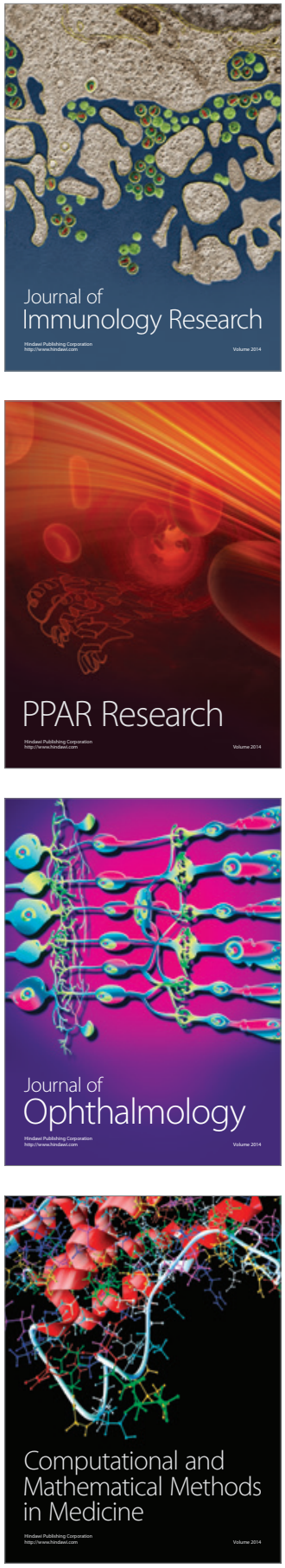

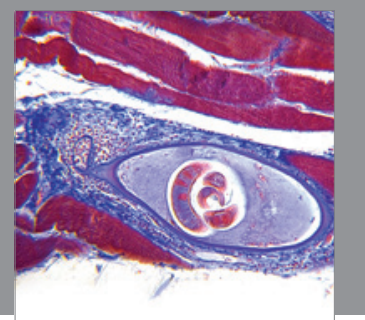

Gastroenterology

Research and Practice
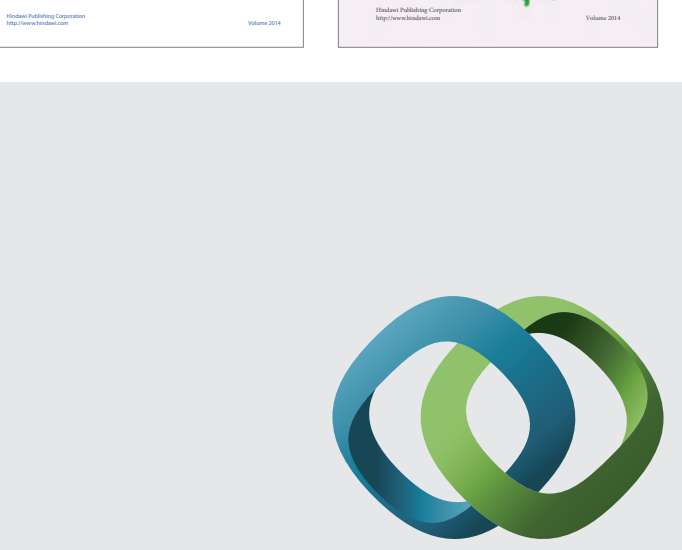

\section{Hindawi}

Submit your manuscripts at

http://www.hindawi.com
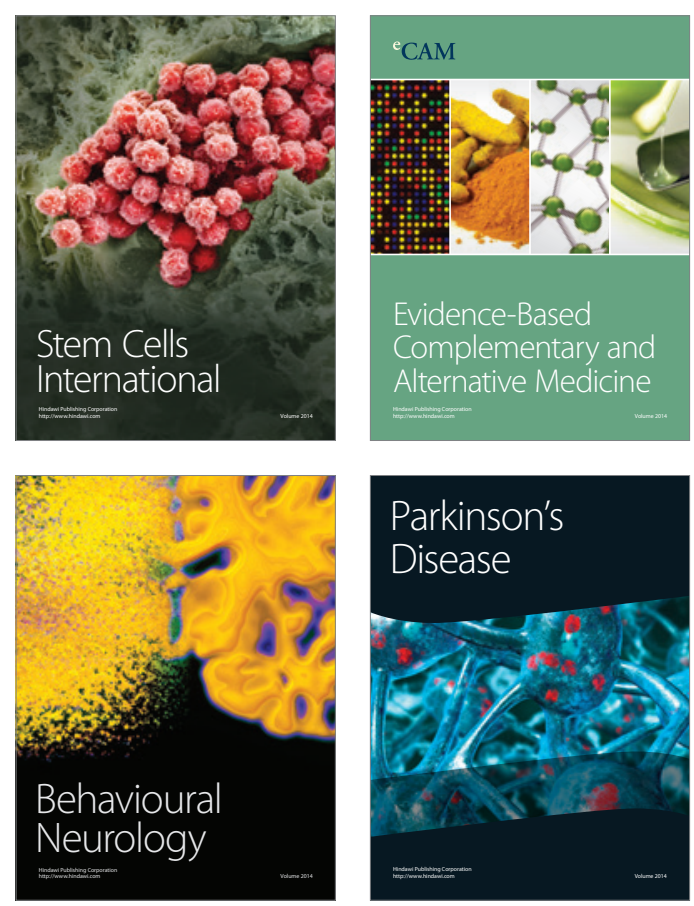

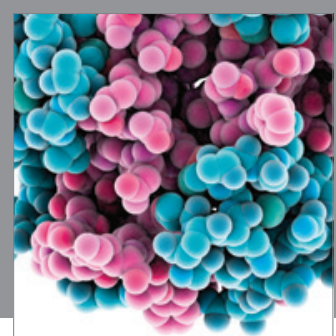

Journal of
Diabetes Research

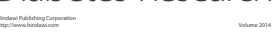

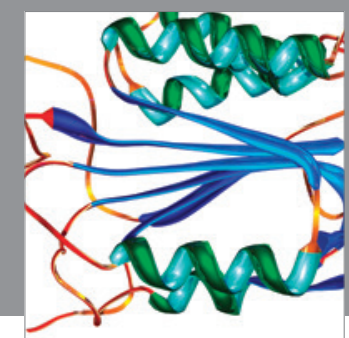

Disease Markers
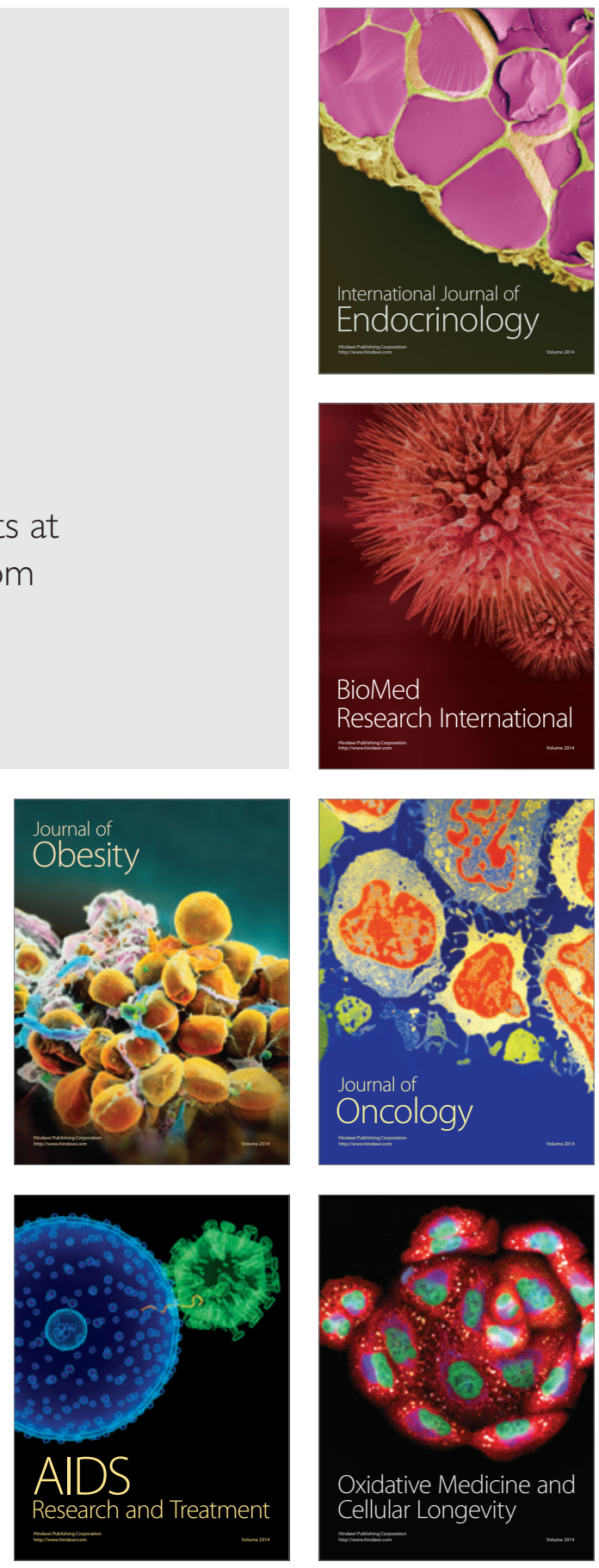